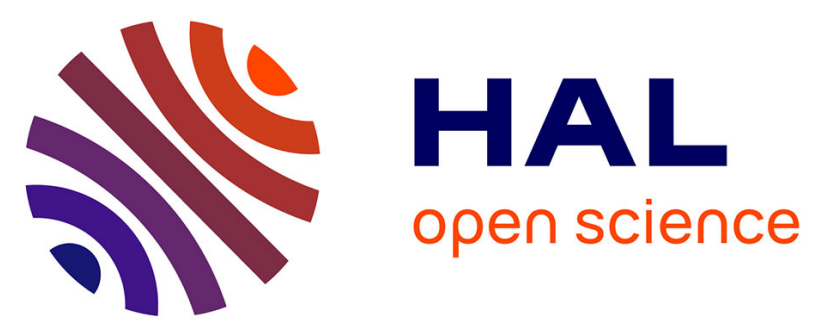

\title{
Estimating the Vertical Structure of Intense Mediterranean Precipitation Using Two X-Band Weather Radar Systems
}

Alexis Berne, Guy Delrieu, Hervé Andrieu

\section{- To cite this version:}

Alexis Berne, Guy Delrieu, Hervé Andrieu. Estimating the Vertical Structure of Intense Mediterranean Precipitation Using Two X-Band Weather Radar Systems. Journal of Atmospheric and Oceanic Technology, 2005, 22 (11), pp.1656 à 1675. 10.1175/JTECH1802.1 . insu-00382098

\section{HAL Id: insu-00382098 \\ https://hal-insu.archives-ouvertes.fr/insu-00382098}

Submitted on 19 Feb 2021

HAL is a multi-disciplinary open access archive for the deposit and dissemination of scientific research documents, whether they are published or not. The documents may come from teaching and research institutions in France or abroad, or from public or private research centers.
L'archive ouverte pluridisciplinaire HAL, est destinée au dépôt et à la diffusion de documents scientifiques de niveau recherche, publiés ou non, émanant des établissements d'enseignement et de recherche français ou étrangers, des laboratoires publics ou privés. 


\title{
Estimating the Vertical Structure of Intense Mediterranean Precipitation Using Two X-Band Weather Radar Systems
}

\author{
A. BERNE \\ Hydrology and Quantitative Water Management Group, Wageningen University, Wageningen, Netherlands \\ G. DELRIEU \\ Laboratoire d'études des Transferts en Hydrologie et Environnement, Grenoble, France
}

H. ANDRIEU

Division Eau, Laboratoire Central des Ponts et Chaussées, Nantes, France

(Manuscript received 25 October 2004, in final form 19 March 2005)

\begin{abstract}
The present study aims at a preliminary approach of multiradar compositing applied to the estimation of the vertical structure of precipitation-an important issue for radar rainfall measurement and prediction. During the HYDROMET Integrated Radar Experiment (HIRE'98), the vertical profile of reflectivity was measured, on the one hand, with an X-band vertically pointing radar system, and, on the other hand, with an X-band RHI scanning protocol radar. The analysis of the raw data highlights the effects of calibration and attenuation problems affecting the measurements of both radar systems. Once the two radar systems have been intercalibrated, various attenuation correction techniques are applied. The comparison of raw, intercalibrated, and corrected radar measurements for the two radar systems stresses the importance of calibration and attenuation correction. The applied corrections improve the consistency of the vertical profile of reflectivity that is measured by the two radar systems. However, a significant uncertainty remains when strong radar signal attenuations occur.
\end{abstract}

\section{Introduction}

The interpretation of the radar measurement in terms of rainfall is complex because it depends on 1) the rainfall variability at all scales (elementary scale of the raindrops, radar resolution volume, storm, ...), 2) the detection domain, which is mainly defined by the surrounding relief and land use (urbanization), and 3) the parameters of the radar system employed. In mountainous regions and/or in urban areas, the visibility problem ( 2 above) is certainly an important limitation to the implementation of S-band radar networks both in economical and technical terms. On the other hand, working at shorter wavelengths ( $\mathrm{C}$ or $\mathrm{X}$ band) adds

Corresponding author address: Alexis Berne, Hydrology and Quantitative Water Management Group, Nieuwe Kanaal, 116709 PA Wageningen, Netherlands.

E-mail: Alexis.Berne@wur.nl undesirable attenuation effects that are particularly difficult to cope with. It is anticipated that to solve the rainfall estimation problem in such "rugged" areas, a broad variety of radar systems having different parameters (wavelength, scanning strategy, ...) will be deployed, with an increasing spatial density, in the future. From this perspective, multiradar rainfall estimation is certainly an important subject that requires investigation. It is also a very difficult problem because calibration, space-time sampling, attenuation, vertical profile of reflectivity (VPR), and relief-induced errors are likely to introduce many inconsistencies between the available radar datasets. The following two approaches may be envisaged.

- The first is to process each radar dataset individually using physically based correction schemes in order to develop hydrological products for each radar prior to their spatial merging. This merging could be based, for instance, on quality-control methods relying on in 
situ measurements. This is the manner in which radar composites are presently established for operational radar networks.

- The second approach consists of the simultaneous use of the raw datasets in order to maximize the information that is available at a given point in space for rain-rate estimation; an example of this approach could be the use of volumetric data from two radar systems to improve the VPR estimation in their overlapping detection domains. This "early merging" approach is also suited to radar configurations involving very different scanning strategies (e.g., a conventional scanning radar and a vertically pointing radar).

The present paper offers a preliminary contribution to this topic with a multiradar measurement configuration implemented during the HYDROMET Integrated Radar Experiment (HIRE'98; Uijlenhoet et al. 1999) in Marseille, France. The main objective of the work is to provide reliable estimates of the vertical structure of intense Mediterranean precipitation. The knowledge of the VPR is certainly a very important issue for radar rain measurement (Joss and Waldvogel 1990; Fabry and Zawadzki 1995; Pellarin et al. 2002; Berne et al. 2004) and prediction. Two X-band radar systems, separated by $11 \mathrm{~km}$, with one operating in vertical mode and the other in range-height indicator (RHI) mode in the direction of the vertically pointing radar, provide $1 \mathrm{D}$ and $2 \mathrm{D}$ vertical cuts of the atmosphere that will be presented in section 2. Section 3 is devoted to the description of the models that are used to parameterize the drop size distribution (DSD) and the relationships between the bulk radar observables at attenuating wavelengths. A presentation of various attenuation correction schemes developed in previous work (Marzoug and Amayenc 1994; Serrar et al. 2000; Vignal et al. 2003 ) is also given. In section 4, calibration and attenuation corrections are performed accordingly for the two radar systems. In section 5, the efficiency of these corrections is assessed using the height-time indicators (HTIs) estimated separately. Our conclusions and perspectives are reported in section 6 .

\section{Dataset}

\section{a. The HYDROMET Integrated Radar Experiment}

The HYDROMET project, funded by the Environment Program of the European Union, gathered 12 scientific groups from six European countries (France, Greece, Italy, Slovenia, Spain, and the United Kingdom). The main objective was to promote the hydrological applications of weather radar, through the de-

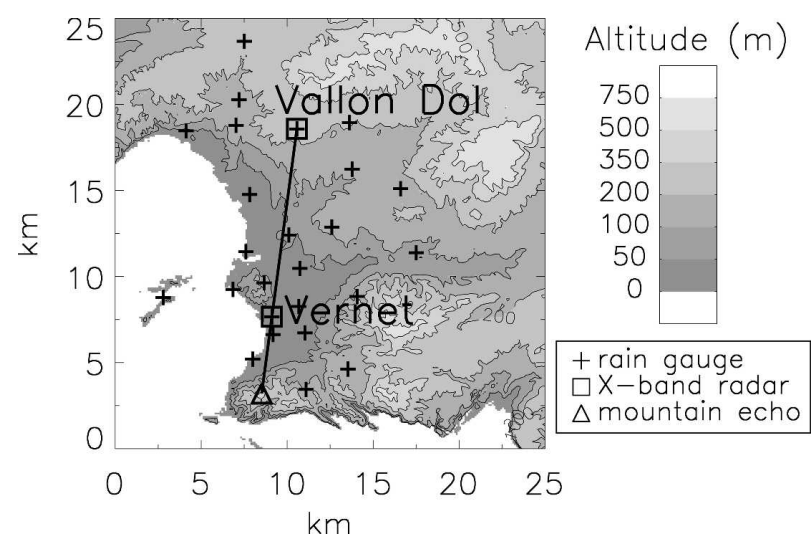

FIG. 1. Topography of Marseille and location of the measurement devices.

velopment of real-time flood forecasting systems, based on optimized weather radar data and various rainfallrunoff models. A major step in this project was the organization of a joint radar hydrological field experiment-HIRE'98. The objectives of this experiment were to share and to integrate the respective works and sensors of the project members for the improvement of radar data quality and urban hydrological modeling (Uijlenhoet et al. 1999).

The HIRE'98 experiment took place from 1 September to 30 November 1998 in Marseille. Because of its interesting hydrometeorological environment and infrastructure, this town was selected as the experimental site. Marseille is located on the French Mediterranean coast (Fig. 1). The Mediterranean climate is characterized by a dry summer and severe thunderstorms, which occur around the end of summer and the beginning of autumn. Marseille has an annual rain total of approximately $550 \mathrm{~mm}$, falling in about $100 \mathrm{~h}$. There are typically about 10 rain events per year with maximum intensities up to $100 \mathrm{~mm} \mathrm{~h}^{-1}$ in $6 \mathrm{~min}$. To anticipate and manage flooding hazards, the city of Marseille has set up a 6-min, real-time telemetering network of 25 tipping-bucket rain gauges (Fig. 1) and about 100 stage recorders. This network is complemented by dedicated warning bulletins and the Meteo+ (radar, satellite, and lightning) operational data, both provided by MétéoFrance. During HIRE'98, the operational networks of rain gauges and stage recorders were complemented with two light configuration weather radar systems (see Fig. 1): (i) a mobile $X$-band vertically pointing radar system (hereafter the X-Pointer radar), installed at the site of Vernet, the location of the city sewage network management headquarters, and (ii) a mobile X-band radar system located at the site of Vallon Dol, $11 \mathrm{~km}$ north of the Vernet site. The latter location was previously used for urban rainfall measurement over the city 
of Marseille with an X-band radar system (Delrieu et al. 1997). This radar was operated with an RHI scanning protocol (hence, it will be designated as X-RHI radar in the following). The beam axis of the X-Pointer radar was intentionally set in the scanning plane of the $\mathrm{X}$-RHI radar. The X-Pointer radar belongs to the Water and Environmental Management Research Center of the University of Bristol, in the United Kingdom, and the X-RHI radar to the Laboratoire d'étude des Transferts en Hydrologie et Environnement in Grenoble, France. The technical characteristics of these radar systems are listed in Table 1 . Their relative configuration is presented in Fig. 2. In addition to these radar systems, there were two weather stations at each of the two sites. In the following study, we used the data from the radar systems, the Vallon Dol weather station rain gauge, and the operational rain gauge network.

\section{b. Selected rain events}

We have concentrated on the three most intense rain events of the HIRE'98 experiment, which occurred on 7 September 1998 (hereafter the 09/07 rain event), 11 September 1998 (hereafter the 09/11 rain event), and 5 October 1998 (hereafter the 10/05 rain event). Figure 3 displays the total rain accumulations over the area for the three rain events, using the kriging technique for mapping the individual rain gauge estimates (Creutin and Obled 1982). The 09/07 rain event was very intense. However, because of a problem with the X-RHI radar, we have focused on a period of approximately $2 \mathrm{~h}$ (142 $\mathrm{min})$. The rain gauge network recorded maximum rain intensity peaks of about $70 \mathrm{~mm} \mathrm{~h}^{-1}$ in $6 \mathrm{~min}$, with total accumulations varying between 2.8 and $38.6 \mathrm{~mm}$ among the 25 rain gauges and maximum horizontal gradients of about $30 \mathrm{~mm}$ within $10 \mathrm{~km}$. The 09/11 rain event lasts about $3 \mathrm{~h}$. The maximum rain intensity peaks recorded were about $60 \mathrm{~mm} \mathrm{~h}^{-1}$ in $6 \mathrm{~min}$, with total accumulations varying between 16.4 and $39.6 \mathrm{~mm}$, and maximum horizontal gradients of about $15 \mathrm{~mm}$ within $10 \mathrm{~km}$. The 10/05 rain event lasts about $4 \mathrm{~h}$ and $30 \mathrm{~min}$. The maxi-

TABLE 1. Radar parameters.

\begin{tabular}{lcc}
\hline \multicolumn{1}{c}{ Parameter } & X-Pointer & X-RHI \\
\hline Scan type & HTI & RHI \\
Frequency $(\mathrm{GHz})$ & 9.4 & 9.4 \\
Wavelength $(\mathrm{cm})$ & 3.2 & 3.2 \\
Peak power $(\mathrm{kW})$ & 25 & 40 \\
Pulse length $(\mu \mathrm{s})$ & 0.05 & 2 \\
PRF $(\mathrm{Hz})$ & 650 & 500 \\
Antenna size $(\mathrm{m})$ & 1.2 & 1.2 \\
Gain $(\mathrm{dB})$ & 38 & 38.8 \\
Beamwidth $\left(^{\circ}\right)$ & 1.8 & 1.8 \\
\hline
\end{tabular}

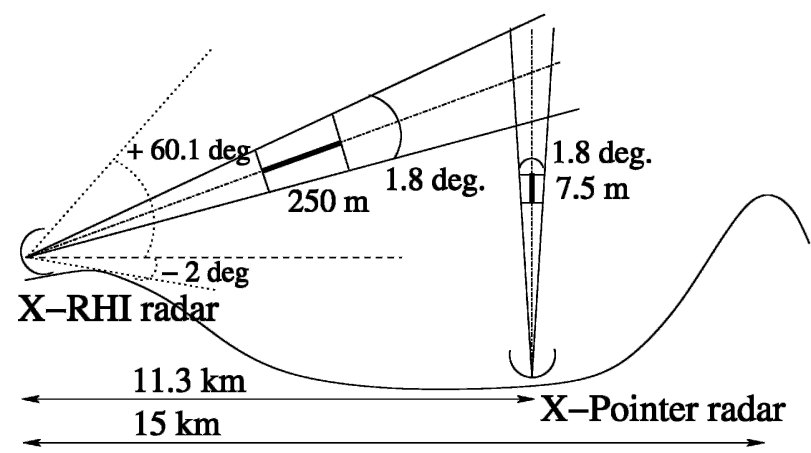

FIG. 2. Configuration of the two radar systems.

mum rain intensity peaks recorded were about $40 \mathrm{~mm}$ $\mathrm{h}^{-1}$ on $6 \mathrm{~min}$, with total accumulations varying from 0 to $60 \mathrm{~mm}$ and maximum horizontal gradients of about $40 \mathrm{~mm}$ within $5 \mathrm{~km}$.

To further quantify the magnitude of the rain events, we present the path-integrated attenuation (PIA) affecting the X-RHI radar measurements. Using the concepts of the "mountain reference technique" ("MRT") proposed for the Marseille area by Delrieu et al. (1997), and further developed by Delrieu et al. (1999a) and Serrar et al. (2000), the PIA was estimated between the X-RHI radar and the mountain echoes, located at a distance of about $15 \mathrm{~km}$ from the radar site (Fig. 1). The method used to estimate the PIA from mountain radar echoes will be recalled in section $4 \mathrm{a}(1)$. Figure 4 presents the evolution of the estimated PIA with time, for the three selected rain events. The strong attenuation occurring during the three events can be easily observed. For the 09/07 rain event, the maximum (two way) PIA is about $30 \mathrm{~dB}$. The corresponding pathaveraged rain intensity derived from the rain gauge network is about $40 \mathrm{~mm} \mathrm{~h}^{-1}$ over the $15-\mathrm{km}$ range. For the 09/11 rain event, the maximum PIA is about $20 \mathrm{~dB}$ and the path-averaged rain intensity is about $30 \mathrm{~mm} \mathrm{~h}^{-1}$ over the $15-\mathrm{km}$ range. For the $10 / 05$ rain event, the maximum PIA is about $15 \mathrm{~dB}$ and the corresponding path-averaged rain intensity is about $20 \mathrm{~mm} \mathrm{~h}^{-1}$. Such results are consistent with the attenuation-rain rate relationships to be presented in section 3 .

\section{c. Raw VPR data analysis}

The two radar systems described previously provide different measurements. The X-Pointer radar provides HTIs, that is, the evolution of the VPR with time. Because the beam axis of the X-Pointer radar coincides in the scanning plane of the X-RHI radar, it is possible to extract the VPR from the X-RHI radar data above the Vernet site. The possibility to observe and analyze measurements of the same region of the atmosphere, 

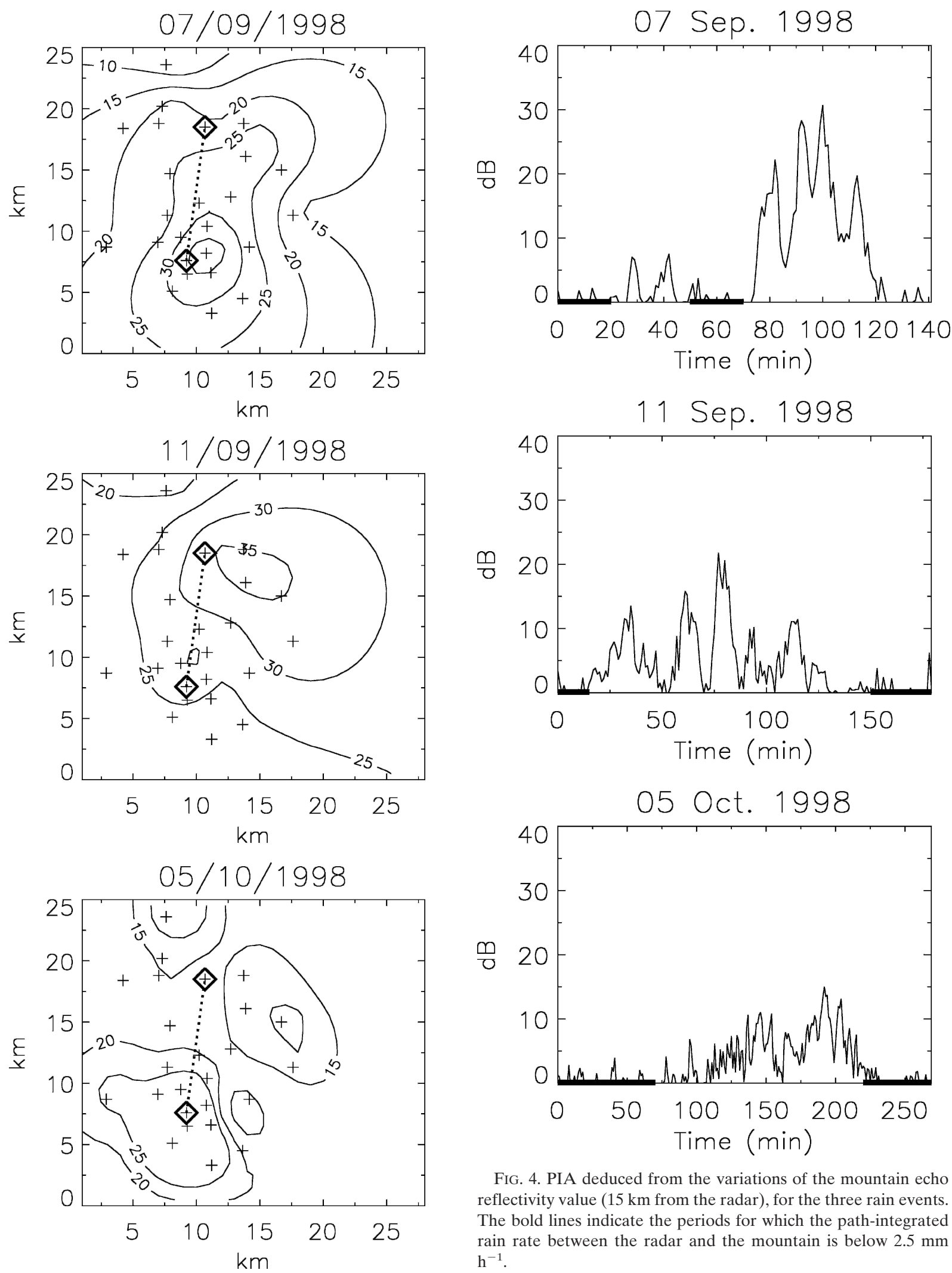

FIG. 4. PIA deduced from the variations of the mountain echo reflectivity value ( $15 \mathrm{~km}$ from the radar), for the three rain events. The bold lines indicate the periods for which the path-integrated rain rate between the radar and the mountain is below $2.5 \mathrm{~mm}$

FIG. 3. Total accumulations $(\mathrm{mm})$ for the three rain events: the rain gauge locations $(+)$ and the X-band radar systems $(\diamond)$. 

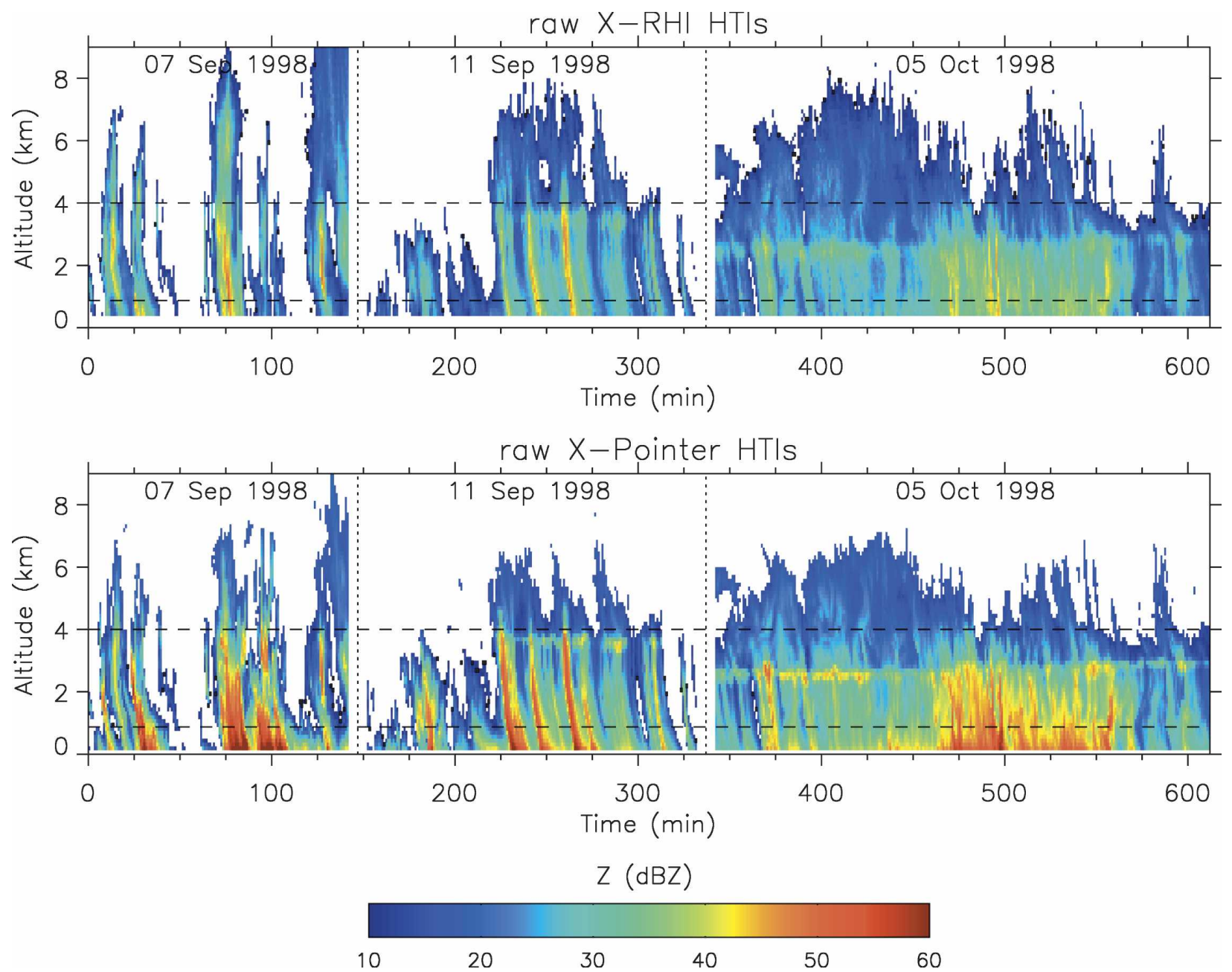

FIG. 5. HTIs derived from raw X-RHI and X-Pointer measurements for the three rain events. The dashed lines indicate the range of altitude $(0.8 \leq h \leq 4 \mathrm{~km})$ on which the comparison criteria are calculated.

and, hence, the same precipitation with two groundbased radar systems, offers an interesting opportunity to study multiradar compositing, with the objective of characterizing the vertical structure of intense Mediterranean precipitation.

The first step of the analysis consists of the comparison of the raw HTI obtained from the two radar systems to emphasize the similarities and the differences between the two datasets. To perform such a comparison, we have first to homogenize the data, in terms of their temporal and spatial resolution. The X-Pointer radar HTIs have a temporal resolution of $4 \mathrm{~s}$ and a radial resolution of $7.5 \mathrm{~m}$. The HTIs derived from $\mathrm{X}$-RHI radar have a temporal resolution of $1 \mathrm{~min}$ and a radial resolution of $125 \mathrm{~m}$. The X-Pointer radar data were, therefore, averaged to obtain the temporal and spatial resolution of $1 \mathrm{~min}$ and $125 \mathrm{~m}$, respectively. It was observed that the lowest elevation angle X-RHI measurements are affected by screening effects attributed to a small hill in the vicinity of the Vallon Dol radar site. Subsequently, the X-RHI radar HTIs are displayed only above an altitude of about $500 \mathrm{~m}$ (see Fig. 5). To quantify the comparison of the two datasets, we shall use the following criteria:

- the determination coefficient, that is, the square of the correlation coefficient;

- the Nash criterion (Nash and Sutcliffe 1970), also called efficiency

$$
\text { Eff }=1-\frac{\sum_{i=1}^{n}\left(Y_{i}-X_{i}\right)^{2}}{\sum_{i=1}^{n}\left(X_{i}-\bar{X}\right)^{2}} ; \text { and }
$$

- the root-mean-square error 


$$
\text { rmse }=\sqrt{\frac{1}{n-1} \sum_{i=1}^{n}\left(Y_{i}-X_{i}\right)^{2}},
$$

where $X$ is the reference variable, $\bar{X}$ is its mean, and $Y$ is the tested variable. These criteria will be calculated with the two radar measurements (expressed in $\mathrm{dBZ}$ ) for a range of altitudes starting from $0.8 \mathrm{~km}$, to avoid ground echoes contamination in the X-RHI data [see section $4 \mathrm{a}(1)$ ], up to $4 \mathrm{~km}$ to be below or just at the altitude of the melting layer (see section 3a). This analysis provides information on the structure of the rain events themselves and on the errors affecting the two radar systems.

The HTIs of the three rain events, displayed in Fig. 5, highlight the differences in their structure. The 09/07 rain event is clearly a convective event, with a high vertical development reaching an altitude of about 7-8 $\mathrm{km}$, the presence of intense convective cells, and a significant intermittency. The 09/11 rain event is a "mixed" event, presenting intense cells, but also a light bright band associated to the melting layer at an altitude of about $4 \mathrm{~km}$. The 10/05 rain event is a stratiform event, with a strong bright band at an altitude of about $3 \mathrm{~km}$. The last two events exhibit less intermittency and lower vertical developments. These three rain events are contrasted and thought to be representative of the intense Mediterranean precipitation.

Figure 5 shows the general similarities between the measurements of the two radar systems. For all of the rain events, the two radar systems measure the same general structure for the HTIs, especially in terms of temporal dynamics of the VPR. This cofluctuation of the two measurements is quantified via the scatter diagrams and the comparison criteria presented in Fig. 6. The values of the determination coefficient $(0.18,0.46$, and 0.73 for the three events, respectively) are relatively low, though significantly different from 0 . The more convective the events are, the less the HTIs cofluctuate. Temporal integration over a 5-min time step allows for significant improvement of the cofluctuation between the two HTI series (determination coefficients of $0.26,0.64$, and 0.88 ), mostly by reducing the effects of imprecise time synchronization between the two measurements. However, the efficiency and the rmse are not significantly improved, an indication of the influence of other sources of bias.

Other forms of discrepancy may be inferred from Fig. 5. The first appears in the range of reflectivity values. For the three rain events, the X-Pointer radar provides stronger reflectivities than the $\mathrm{X}$-RHI radar. For the $09 / 07$ (09/11 and 10/05, respectively) rain event, the maximum value of reflectivity is about 68 (65 and 53) $\mathrm{dBZ}$ for the X-Pointer radar, while it is 50 (47 and 48)
$\mathrm{dBZ}$ for the X-RHI radar. This higher level of reflectivity for the X-Pointer radar is consistent across all of the HTI, highlighting the problem of calibration for the two radars, in particular, the X-Pointer radar.

Another form of discrepancy comes from the fact that some cells are either not measured or are significantly underestimated by one of the radars. For example, during the 09/07 rain between time steps 90 and 110 , the X-Pointer radar measures a strong cell, even though the X-RHI radar measures almost nothing because of the attenuation occurring between the Vernet and the Vallon Dol sites. Alternatively, between time steps 70 and 90, the vertical development of the cell is about $6 \mathrm{~km}$ for the X-Pointer radar, while it is about 8 $\mathrm{km}$ for the X-RHI radar. We find the same problem during the 09/11 and 10/05 rain events - the vertical development of the cells is about $6 \mathrm{~km}$ for the X-Pointer radar, while it is about $7.5 \mathrm{~km}$ for the X-RHI radar. These effects are directly related to the attenuation suffered by X-band radars, particularly when high rainfall intensities occur.

Significant reflectivity enhancement may be observed in the lowest levels of the VPR measured by the $\mathrm{X}$-Pointer radar, a feature that cannot be confirmed by the X-RHI radar because of the mentioned screening effect.

Finally, this analysis of the raw VPR data emphasizes the different sources of error affecting the measurements of the two radars and the next section presents the methods that are used to correct for them, in order to obtain reliable estimates of the VPR.

\section{Rain measurement at attenuating wavelengths}

The comparison of the two raw radar datasets highlights the attenuation affecting these measurements. In the present section, we first explain the method performed to obtain consistent relations between the radar observables using a given drop size distribution. In a second part, we detail the algorithms applied to correct for the attenuation.

\section{a. $(Z, k, R)$ relations}

The knowledge of the microstructure of rainfall is essential for active microwave remote sensing. Particularly, the properties (size, shape, etc...) of the raindrops form the physical basis of weather radar measurement (e.g., Doviak and Zrnic 1993). In this section, we focus on the DSD and on the estimation of consistent $(Z, k, R)$ relations using a given DSD (Delrieu et al. 1991,1999a). Sempere-Torres et al. (1994) proposed to express the DSD as follows: 

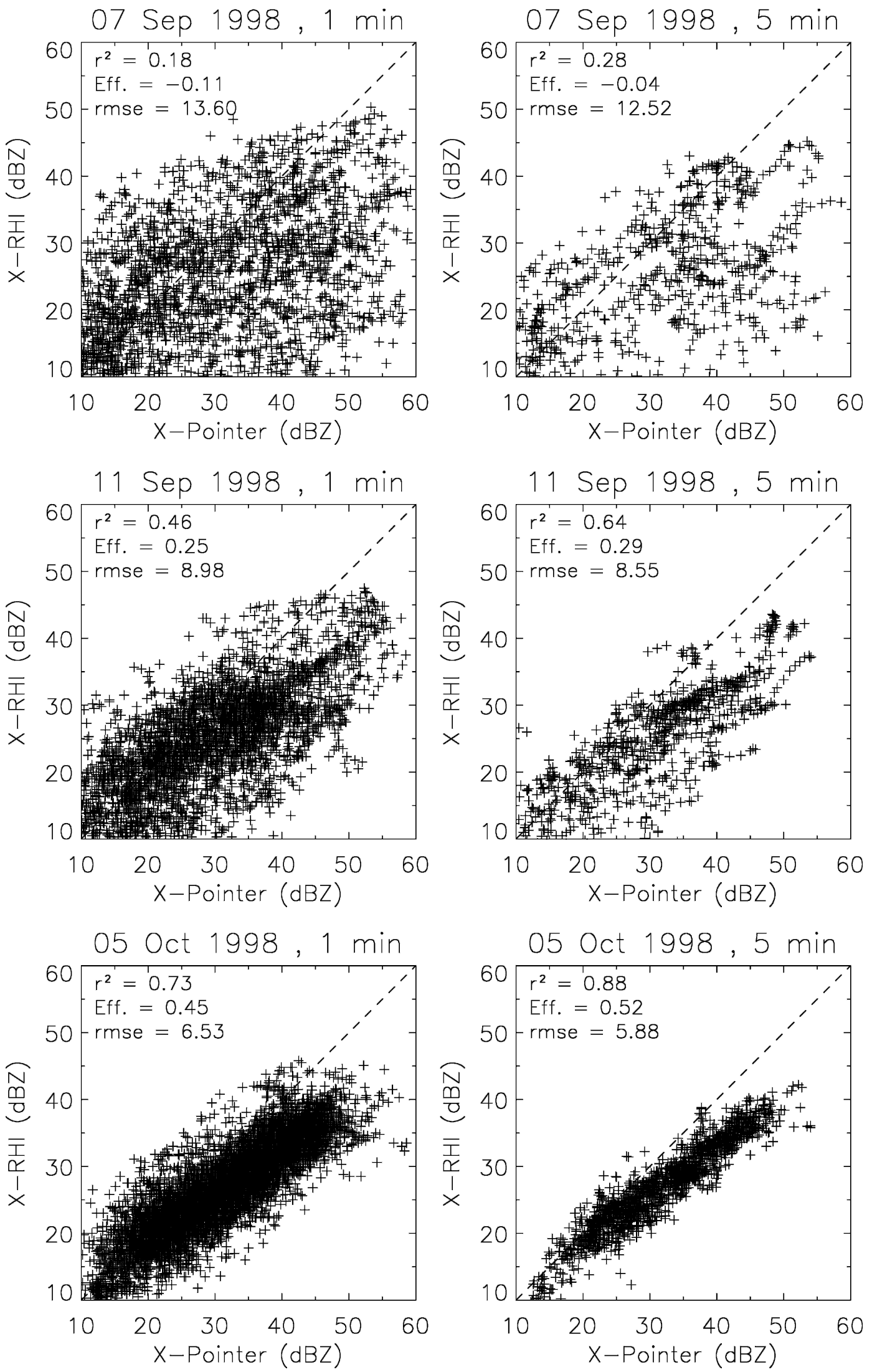

FIG. 6. Scatter diagrams for HTIs derived from raw X-RHI and X-Pointer measurements for the three rain events, at a time step of (left) 1 and (right) $5 \mathrm{~min}$. Only the points above $0.8 \mathrm{~km}$ and below $4 \mathrm{~km}$ of altitude are considered. 


$$
N(D, R)=R^{\alpha} g\left(D R^{\beta}\right),
$$

where $D$ is the raindrop diameter and $R$ the rainfall intensity; $R$ is a rain-rate integral variable and corresponds approximately to the third-order weighted moment of the DSD,

$$
R=\frac{\pi}{6} C_{R} \int_{D_{\min }}^{D_{\max }} D^{3} N(D, R) V_{t}(D) d D,
$$

where $D_{\min }$ and $D_{\max }$ are the minimum and maximum diameters of the raindrops, respectively, $V_{t}$ is the terminal velocity for a raindrop of $D$ diameter, and $C_{R}$ is a constant depending on the units employed. If $R$ is in $\mathrm{mm} \mathrm{h}^{-1}, V_{t}$ in $\mathrm{m} \mathrm{s}^{-1}, N(D, R)$ in $\mathrm{cm}^{-4}$, and $D$ is in $\mathrm{cm}$, the value of $C_{R}$ is $3.6 \times 10^{6}$. The terminal velocities were obtained from Beard's model (Beard 1976). If the general function $g$ can be described by an exponential model, the DSD model $N(D, R)$ can be written as

$$
N(D, R)=C R^{\alpha} \exp \left(-\gamma R^{\beta} D\right) .
$$

Delrieu et al. (1999a) proposed to fit the shape parameters $\gamma$ and $\beta$ using experimental DSD and then to calculate $N_{0}=C R^{\alpha}$ for a range of rain rates $(5-100 \mathrm{~mm}$ $\mathrm{h}^{-1}$ ) in order to satisfy the rain-rate integral Eq. (4),

$$
N_{0}=R /\left[\frac{\pi}{6} C_{R} \int_{D_{\min }}^{D_{\max }} D^{3} \exp \left(-\gamma R^{\beta} D\right) V_{t}(D) d D\right] .
$$

A power-law relationship between $N_{0}$ and $R$ with $C$ and $\alpha$ as parameters is fitted to the obtained plots to provide a rain-scaled DSD.

Considering a given DSD, it is possible to express the equivalent reflectivity factor $Z$ and the attenuation coefficient $k$ as function of the DSD:

$$
\begin{gathered}
Z=C_{Z} \int_{D_{\min }}^{D_{\max }} N(D, R) \sigma_{b}(D) d D, \\
k=C_{k} \int_{D_{\min }}^{D_{\max }} N(D, R) Q_{t}(D) d D,
\end{gathered}
$$

where $\sigma_{b}$ and $Q_{t}$ are the backscattering and total attenuation cross sections, respectively; $C_{Z}$ and $C_{k}$ are constants depending on the units employed. If $Z$ is in $\mathrm{mm}^{6} \mathrm{~m}^{-3}, k$ is in $\mathrm{dB} \mathrm{km}{ }^{-1}$, and $\sigma_{b}$ and $Q_{t}$ are in $\mathrm{cm}^{2}$, then the values of $C_{Z}$ and $C_{k}$ are $0.40 \times 10^{12}$ and 0.43 $\times 10^{6}$, respectively. Using the analytical solutions from Mie theory, the $Z$ and $k$ values corresponding to a range of rain rate $\left(5-100 \mathrm{~mm} \mathrm{~h}^{-1}\right)$ can be calculated. Then, the coefficients of the $Z-R$ and $k-R$ power relations are fitted on the previously obtained tables of $(Z$ versus $R$ ) and ( $k$ versus $R$ ), respectively. With such a
TABLE 2. DSD parameterization from Delrieu et al. (1997) and associated $(Z, k, R)$ relations $\left(Z\right.$ is in $\mathrm{mm}^{6} \mathrm{~m}^{-3}, k$ is in $\mathrm{dB} \mathrm{km}^{-1}$, and $R$ is in $\mathrm{mm} \mathrm{h}^{-1}$ ).

\begin{tabular}{cccc}
\hline \hline$\gamma$ & $\beta$ & $Z-R$ & $k-R$ \\
\hline 39.9 & -0.195 & $Z=236 R^{1.53}$ & $k=7.3 \times 10^{-3} R^{1.25}$ \\
\hline
\end{tabular}

procedure, the DSD and the $(Z, k, R)$ relations are dependent on two parameters, $\gamma$ and $\beta$.

The approach presented in this paper has been tested with two different DSD parameterizations. The first one ("Marseille," Delrieu et al. 1997) corresponds to stratiform rain and the second to convective rain (Salles et al. 1999). However, the results are similar for both, suggesting that the influence of the DSD parameterization is limited (see Berne et al. 2004, in which related results also show limited dependency on the DSD parameterization). Therefore, in the following we shall consider only the first DSD parameterization, which corresponds to a mean DSD for Mediterranean rainfall in this area. Both $(\gamma, \beta)$ and the deduced $Z-k-R$ relations are presented in Table 2. The $Z-R$ relation is close to the widely used one $Z=200 R^{1.6}$ (Marshall et al. 1955). The relations are adapted to attenuating wavelengths and are consistent with the rainfall integral equation. We shall suppose hereafter that the DSD is uniform in space and consistent throughout the rain event. It is a strong assumption, certainly incorrect in the case of cold clouds melting layer within which both ice and liquid phases are present (above and below the melting layer, respectively). However, we are interested in the lower part of the VPR for hydrological applications (e.g., Berne et al. 2004). Moreover, the available dataset does not allow an improved parameterization of the DSD. Consequently, as already mentioned, our quantitative analysis will be performed up to an altitude of $4 \mathrm{~km}$ (about the top of the melting layer for the 09/11 rain event), in order to limit the influence of the bright band on the attenuation correction.

\section{b. Attenuation correction}

In this section, we detail the different attenuation correction algorithms that have been applied: (i) the classical algorithm derived from the analytical solution proposed by Hitschfeld and Bordan (1954; hereafter HB algorithm), (ii) an algorithm proposed by Marzoug and Amayenc (1994; hereafter MA algorithm), which makes use of a PIA estimate that is possibly available at a given range, and (iii) an algorithm based on an inverse method proposed by Vignal et al. (2003; hereafter VADC algorithm). 


\section{1) The Hitschfeld-Bordan Algorithm}

We define the measured radar reflectivity factor as follows:

$$
Z_{m}(r)=\frac{P_{r} r^{2}}{C}
$$

where $P_{r}$ is the power received by the radar and $C$ the weather radar constant. Let us also define the apparent radar reflectivity factor as follows:

$$
Z_{a}(r)=Z(r) \epsilon_{c} A(r),
$$

where $\epsilon_{c}$ represents the radar calibration error factor; $A(r)$ is the two-way attenuation factor:

$$
A(r)=\exp \left[-\frac{2 \ln (10)}{10} \int_{0}^{r} k(s) d s\right] .
$$

Note that the PIA variable (expressed in $\mathrm{dB}$ ) used throughout the text corresponds to $\operatorname{PIA}_{\mathrm{dB}}(r)=-10$ $\log _{10}[A(r)]$. In (11), $k$ is the one-way attenuation coefficient $\left(\mathrm{dB} \mathrm{km}^{-1}\right)$. In the following, $[2 \ln (10)] / 10$ will be approximated by 0.46 . Assuming calibration and attenuation to be the dominant error sources in the considered radar configuration may lead to write $Z_{a}=Z_{m}$. We also assume power-law relationships for the variables $(Z, k, R)$ and, thus, may write

$$
Z=a R^{b} \quad Z=c k^{d} \quad k=e R^{f} .
$$

So (11) may be expressed as follows:

$$
A(r)=\exp \left\{-0.46 \int_{0}^{r}\left[\frac{Z(s)}{c}\right]^{1 / d} d s\right\} .
$$

Using (13) and (10) yields the following differential equation (Marzoug and Amayenc 1994):

$$
\frac{d A(r)^{1 / d}}{d r}=-\frac{0.46}{d}\left[\frac{Z_{m}(r)}{\epsilon_{c} c}\right]^{1 / d} .
$$

We now take into consideration the range $r_{0}$ where the radar reflectivity factor sampling is started or where the reflectivity factors can be considered free from ground returns resulting from the sidelobes of the beam patterns. In the following, $r_{0}$ is referred to as the blind range. Integrating (14) between $r_{0}$ and $r$ yields

$$
A(r)=\left[A\left(r_{0}\right)^{1 / d}-\frac{S\left(r_{0}, r\right)}{\epsilon_{c}^{1 / d}}\right]^{d},
$$

where

$$
S\left(r_{0}, r\right)=\frac{0.46}{d} \int_{r_{0}}^{r}\left[\frac{Z_{m}(s)}{c}\right]^{1 / d} d s
$$

$A\left(r_{0}\right)$ represents the attenuation in the blind range and is called the preliminary attenuation hereafter. Combining (10) with (15) and (16) yields

$$
Z(r)=\frac{Z_{m}(r)}{\left\{\left[A\left(r_{0}\right) \epsilon_{c}\right]^{1 / d}-\frac{0.46}{d} \int_{r_{0}}^{r}\left[Z_{m}(s) / c\right]^{1 / d} d s\right\}^{d}} .
$$

This formulation is very similar to the one proposed by Hitschfeld and Bordan (1954) and is designated as the HB solution herein, or, when numerical implementation is considered, the HB algorithm. This analytical solution is known to be instable (Hitschfeld and Bordan 1954). For X-band radar systems, Delrieu et al. (1999a) have shown that the implementation of the HB algorithm requires both very accurate radar calibration and PIA values below $10 \mathrm{~dB}$ to provide reliable solutions.

\section{2) The Marzoug-Amayenc algorithm}

To solve the instability problem of the HB solution, various algorithms using the PIA as constraint have been developed. We present in the following, the principle of the algorithm proposed by Marzoug and Amayenc (1994). As previously, calibration and attenuation are assumed to be the dominant error sources and $Z_{a}=$ $Z_{m}$.

Integrating (14) between $r$ and a range $r_{m}$ where the PIA is known yields

$$
A(r)=\left[A\left(r_{m}\right)^{1 / d}+\frac{S\left(r, r_{m}\right)}{\epsilon_{c}}\right]^{1 / d} .
$$

Equation (18), combined with (11), gives the MA algorithm formulation

$$
Z(r)=\frac{Z_{m}(r)}{\left\{\left[A\left(r_{m}\right) \epsilon_{c}\right]^{1 / d}+S\left(r, r_{m}\right)\right\}^{d}} .
$$

As opposed to the HB algorithm, the MA algorithm is unconditionally stable. Moreover, the correction is more efficient when strong attenuation occurs though on the contrary; it is less reliable when attenuation is weak.

\section{3) THE HYBRID ALGORITHM}

The PIA is estimated with the mountain reference technique (detailed in section 4), and the accuracy of these estimations is typically limited to approximately $2.5 \mathrm{~dB}$ (Delrieu et al. 1999b). As explained previously, the MA algorithm is less efficient with low PIA. Therefore, we define a hybrid algorithm (HY algorithm hereafter) that combines the HB algorithm for low PIA and the MA algorithm for higher PIA. The threshold was fixed at $2.5 \mathrm{~dB}$. The $\mathrm{HY}$ algorithm provides a reliable 
correction for all possible PIA values. However, the MA and HY algorithms require PIA measurements that are unlikely to be available in every direction for conventional ground-based radar configurations.

\section{4) The Vignal et AL. Algorithm}

To extend the correction capability of the HB algorithm, Vignal et al. (2003) proposed a new attenuation correction algorithm based on inverse theory. This algorithm is briefly described in the following. Using (12) and (13), (10) can be written for a given rain rate $R$ as

$$
Z_{a}(r)=\epsilon_{c} a R^{b}(r) A\left(r_{0}\right) \exp \left[-0.46 \int_{r_{0}}^{r} e R^{f}(r) d s\right] .
$$

Equation (20) constitutes the so-called attenuation model, that is, it expresses the link between the variable of interest (the rain rate $R$ ) and the data (the apparent radar reflectivity factor $Z_{a}$ ). Because of the nature of the radar system data acquisition, these variables are discrete, with a spatial resolution denoted $\Delta r$ and composed of $n_{p}$ values. We may arrange the components as vectors, and so define $\mathbf{Z}_{a},\left\{Z_{a}(i), i=i_{0}, n_{p}\right\}$ and $\mathbf{R},\{R(i)$, $\left.i=i_{0}, n_{p}\right\}$, where $i_{0}$ corresponds to the blind range. The attenuation model is then discretized and it is possible to express (20) in a general formulation (Vignal et al. 2003),

$$
\mathbf{Z}_{a}=m(\mathbf{R}),
$$

where $m$ represents the model linking $\mathbf{Z}_{a}$ and $\mathbf{R}$. The formulation (21) represents the direct problem. The inverse problem consists in the estimation of the rain-rate profile along a radar tilt knowing the attenuation model $\mathbf{Z}_{a}=m(\mathbf{R})$ and the measured reflectivity factor profile $\mathbf{Z}_{m},\left\{Z_{m}(i), i=i_{0}, n_{p}\right\}$. The originality of the inverse method is to use additional, so-called a priori, information to constrain the solution and, thus, avoid the instability problem of the HB solution. Depending on the inverse problem structure and on the confidence on the data quality, the a priori information may be given various weights in the estimation procedure. Because the attenuation model [Eq. (20)] is underdetermined (as shown by Haddad et al. 1995) and nonlinear, the a priori information is essential in the present context to obtain reliable rain-rate profiles. Menke (1989) demonstrated that the solution vector $\mathbf{R}^{*}$ in terms of maximum likelihood satisfies the following relation:

$$
\begin{aligned}
\mathbf{R}^{*}= & \mathbf{R}_{0}+\mathbf{V}_{R} \mathbf{M}^{\mathbf{T}}\left(\mathbf{M V}_{R} \mathbf{M}^{\mathbf{T}}+\mathbf{V}_{Z}\right)^{-1}\left[\mathbf{Z}_{m}-m\left(\mathbf{R}^{*}\right)\right. \\
& \left.+\mathbf{M}\left(\mathbf{R}^{*}-\mathbf{R}_{0}\right)\right]
\end{aligned}
$$

where the operator $\mathrm{T}$ signifies the transpose of the ma- trix; $\mathbf{R}_{0}$ represents the a priori information vector, $\mathbf{V}_{Z}$ and $\mathbf{V}_{R}$ are the covariance matrices associated to the residuals $\left(\mathbf{Z}_{a}-\mathbf{Z}_{m}\right)$ and $\left(\mathbf{R}-\mathbf{R}_{0}\right)$, respectively, which are assumed to be Gaussian (or at least unimodal) and unbiased. As opposed to the assumptions made for the previous algorithms, the radar measurement error is also taken into account and represented by the residual $\left(\mathbf{Z}_{a}-\mathbf{Z}_{m}\right)$. The matrix of the partial derivatives of $m$ evaluated at $\mathbf{R}^{*}$ is $\mathbf{M}$. Because the model $m$ is nonlinear, (22) must be solved iteratively and the VADC algorithm may be expressed as

$$
\begin{aligned}
\mathbf{R}_{k+1}= & \mathbf{R}_{0}+\mathbf{V}_{R} \mathbf{M}_{k}^{\mathrm{T}}\left(\mathbf{M}_{k} \mathbf{V}_{R} \mathbf{M}_{k}^{\mathrm{T}}+\mathbf{V}_{Z}\right)^{-1}\left[\mathbf{Z}_{m}-m\left(\mathbf{R}_{k}\right)\right. \\
& \left.+\mathbf{M}_{k}\left(\mathbf{R}_{k}-\mathbf{R}_{0}\right)\right],
\end{aligned}
$$

where $\mathbf{R}_{k}$ is the result of the $k$ th iteration and $\mathbf{M}_{k}$ the partial derivatives of the matrix $\mathbf{M}$, evaluated at $\mathbf{R}_{k}$. The VADC algorithm provides the best rain-rate profile in terms of maximum likelihood criterion, having assumed an attenuation model and the statistical characteristics of the residuals $\left(\mathbf{Z}_{a}-\mathbf{Z}_{m}\right)$ and $\left(\mathbf{R}-\mathbf{R}_{0}\right)$.

\section{Application to the VPR estimation with the two $\mathrm{X}$-band radar systems}

To analyze quantitatively indirect measurements, such as radar-rainfall measurements, it is essential to check the calibration of the sensors. Additionally, as the radar systems operate at attenuating wavelengths, it is necessary to correct for the attenuation affecting their measurements, using the algorithms presented in the previous section.

\section{a. X-RHI radar system}

The mountain echo at about $15 \mathrm{~km}$ from the X-RHI radar site (see Fig. 1) provides the opportunity to calibrate the radar, using the MRT described by Serrar et al. (2000).

\section{1) Calibration using the MRT}

Briefly, the PIA values are calculated as the difference between an average dry weather apparent reflectivity of the reference target (a mountain in this context) and the observed value at a given time step during rainy conditions. Figure 4 presents the PIA values deduced from the variations of the mountain echo reflectivity values. The noisy dry weather signal induces a minimum detectable PIA of about $2 \mathrm{~dB}$ and a maximum accuracy of about $2.5 \mathrm{~dB}$, according to Delrieu et al. (1999b). Once PIAs have been estimated, the radar calibration can be performed. Integrating (14) between $r_{0}$ and $r_{m}$ yields the PIA constraint equation 
TABLE 3. X-RHI calibration factor $\varepsilon_{c}$ and corresponding efficiency for the three rain events.

\begin{tabular}{ccc}
\hline \hline Date & Calibration factor $\varepsilon_{c}$ & Efficiency \\
\hline 07 Sep 1998 & $0.661(-1.8 \mathrm{~dB})$ & 0.41 \\
11 Sep 1998 & $0.468(-3.3 \mathrm{~dB})$ & 0.69 \\
05 Oct 1998 & $0.479(-3.2 \mathrm{~dB})$ & 0.28 \\
\hline
\end{tabular}

$$
A_{m}\left(r_{m}\right)^{1 / d}=A\left(r_{0}\right)^{1 / d}-\frac{S\left(r_{0}, r_{m}\right)}{\epsilon_{c}^{1 / d}},
$$

where $A_{m}\left(r_{m}\right)$ is the measured PIA factor; $S\left(r_{0}, r_{m}\right)$ is estimated with the first measured reflectivity profile, which is sufficiently above the mountaintop to avoid ground echo contamination. In our study, the mountaintop has an altitude of about $450 \mathrm{~m}$ and the elevation angle chosen was $2.8^{\circ}$. This profile is referred to hereafter as the "low profile." It is important to note that the corresponding beam altitude over the Vernet site is about $0.8 \mathrm{~km}$, and, hence, the VPRs extracted from the $\mathrm{X}$-RHI measurements will start at $0.8 \mathrm{~km}$. To avoid the blind range attenuation estimation, we have selected only the time steps that have very low rain rates at the $\mathrm{X}$-RHI radar site, as determined with a collocated rain gauge, and, hence, $A\left(r_{0}\right) \simeq 1$. The calibration error factor $\varepsilon_{c}$ is chosen to maximize the consistency of (24) in terms of efficiency over a number of successive time steps. The selection of the calibration error factor represents a global adjustment, taking into account the electronic calibration error itself and also, in part, possible DSD modeling errors. Table 3 gives $\varepsilon_{c}$ and the efficiency values obtained for the three rain events with the DSD chosen. The adjusted calibration error factor is about $-3 \mathrm{~dB}$ for the more stratiform events $(09 / 11$ and 10/05), and about $-2 \mathrm{~dB}$ for the more convective event (09/07). This difference corresponds to the compensation for the error resulting from the DSD parameterization (see Serrar et al. 2000). Once the X-RHI radar data have been calibrated, we have to deal with the attenuation problem.

\section{2) Attenuation correction using the HY AND VADC ALGORITHMS}

Taking into account the strong observed PIAs, the HB algorithm must be discarded for the attenuation correction of the X-RHI data. The strategy followed hereafter is to use the HY algorithm when a PIA estimation is available, that is, for the low profile, and the VADC algorithm elsewhere, that is, for higher elevation angles.

The HY-corrected low profile of reflectivity is transformed to a rain-rate profile, and its accuracy is as- sessed through the comparison with the measurements from the rain gauges located near the axis of the RHI. Figure 7 presents the scatter diagrams between the raw and corrected X-RHI low-profile rain rates and the rain gauge rain rates for the three rain events. For the 09/07, $09 / 11$, and $10 / 05$ rain events, respectively, the determination coefficient increases from $0.05,0.41$, and 0.73 for the raw radar measurements to $0.65,0.66$, and 0.78 once corrected. In the same way, the efficiency increases from $-0.46,-0.32$, and 0.19 for the raw radar measurements to $0.56,0.51$, and 0.75 once corrected. These values show that the HY attenuation correction provides significant skill for the low profile, despite the remaining dispersion in the scatter diagrams notably for the convective event.

The VADC algorithm is then applied to correct the upper-elevation measurements. The hypothesis of unimodal and unbiased residuals required to apply the inverse method have been verified for intense Mediterranean precipitation by Vignal et al. (2003). As highlighted in the previous section, the a priori information is essential for the resolution of the attenuation problem. Because the corrected low profile has proved reliable in comparison with rain gauge measurements, we use it as a priori information for the radar tilt just above the low profile. Then this corrected profile becomes the a priori information for the next profile, and so on. To satisfy the assumption of unbiased residuals $\left(\mathbf{R}-\mathbf{R}_{0}\right)$, it is necessary to correct for the bias resulting from the natural decrease of rain rate with the altitude. To do so, the average vertical rain-rate profile is calculated, using the measured radar reflectivity factors and the $Z-R$ relation. This average vertical rain-rate profile represents the decrease of rain rate with the altitude, despite the effects of attenuation. The unbiased a priori information is obtained by using this average vertical rain-rate profile to condition the corrected below profile. Furthermore, as opposed to the MA algorithm, the VADC algorithm requires knowledge of the attenuation in the blind range. The preliminary attenuation is estimated using the rain gauge-measured rain rate at the radar site and the $k-R$ relation according to the procedure proposed by Delrieu et al. (1997). To illustrate the importance of the correction performed, the raw and the corrected RHI images for a time step with attenuation larger than $15 \mathrm{~dB}$ are displayed in Fig. 8. The correction effects are impressive. No aberrant values could be detected by a visual inspection of the RHI animations. However, to quantify the relevance of the correction performed, it is necessary to compare the HTIs deduced from the corrected X-RHI and X-Pointer data (see section 5 below). 
07 Sep 1998
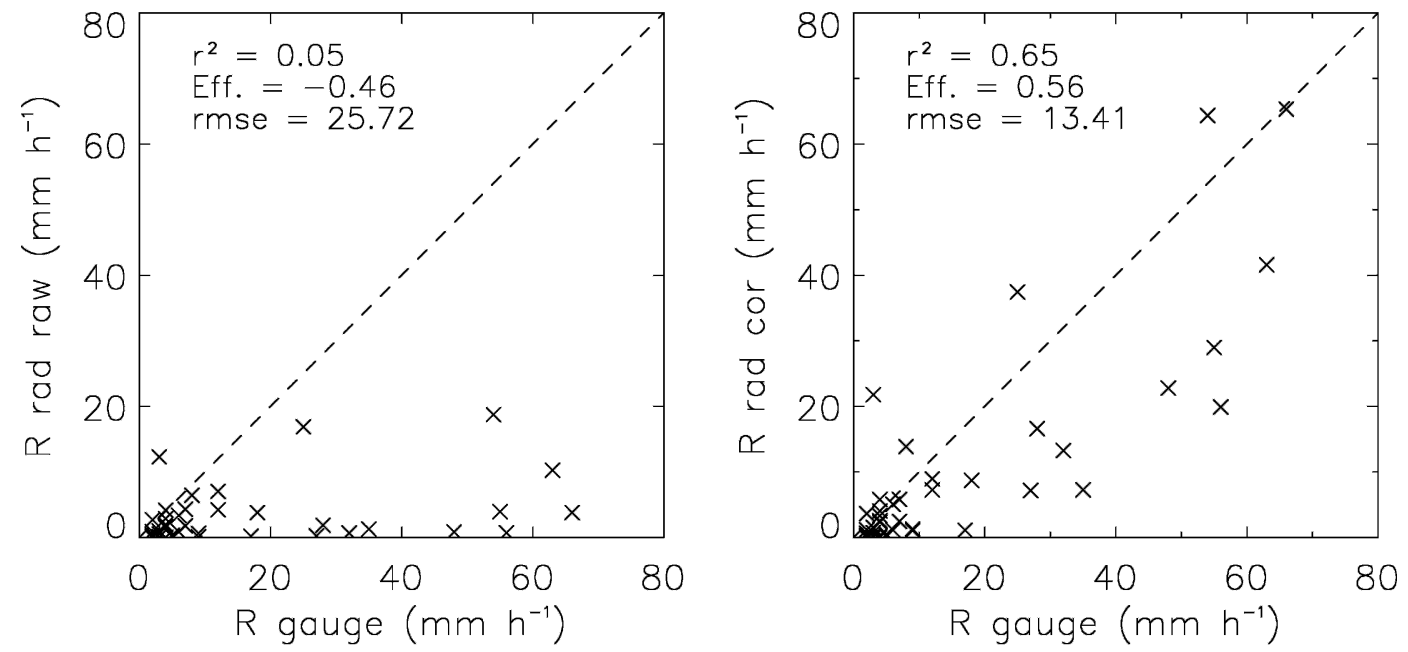

11 Sep 1998
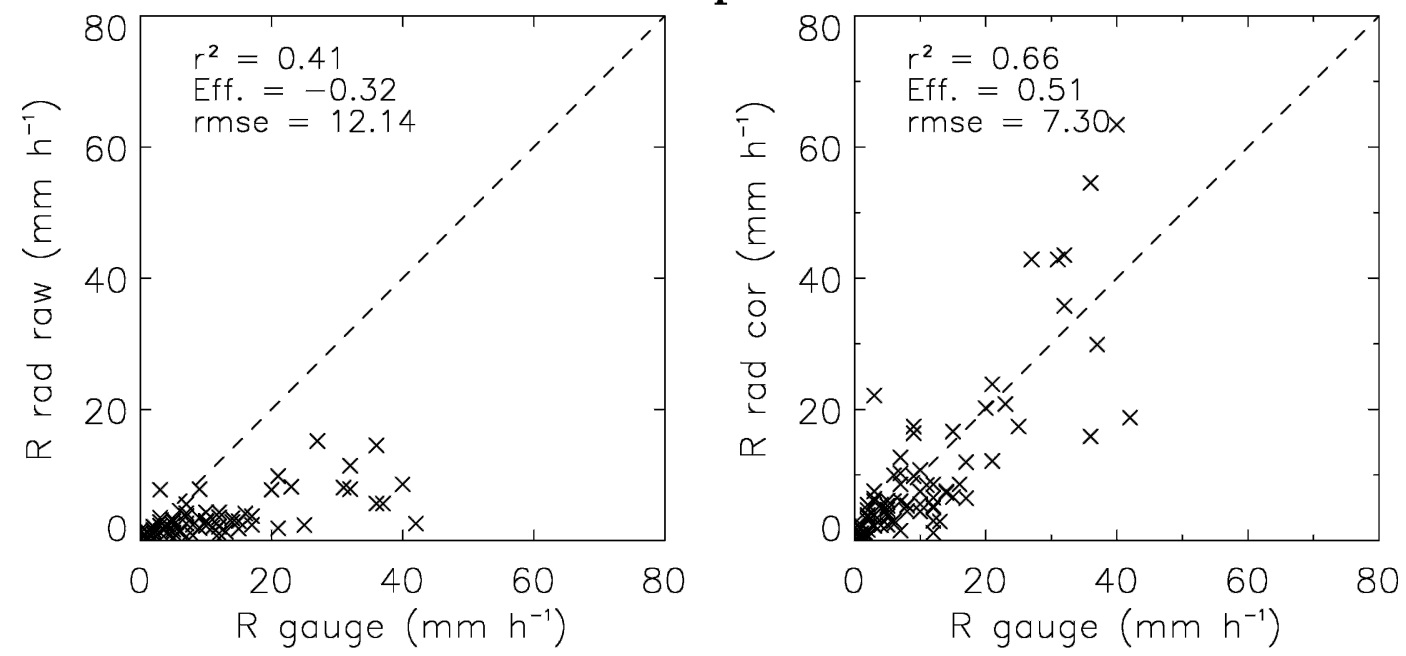

05 Oct 1998
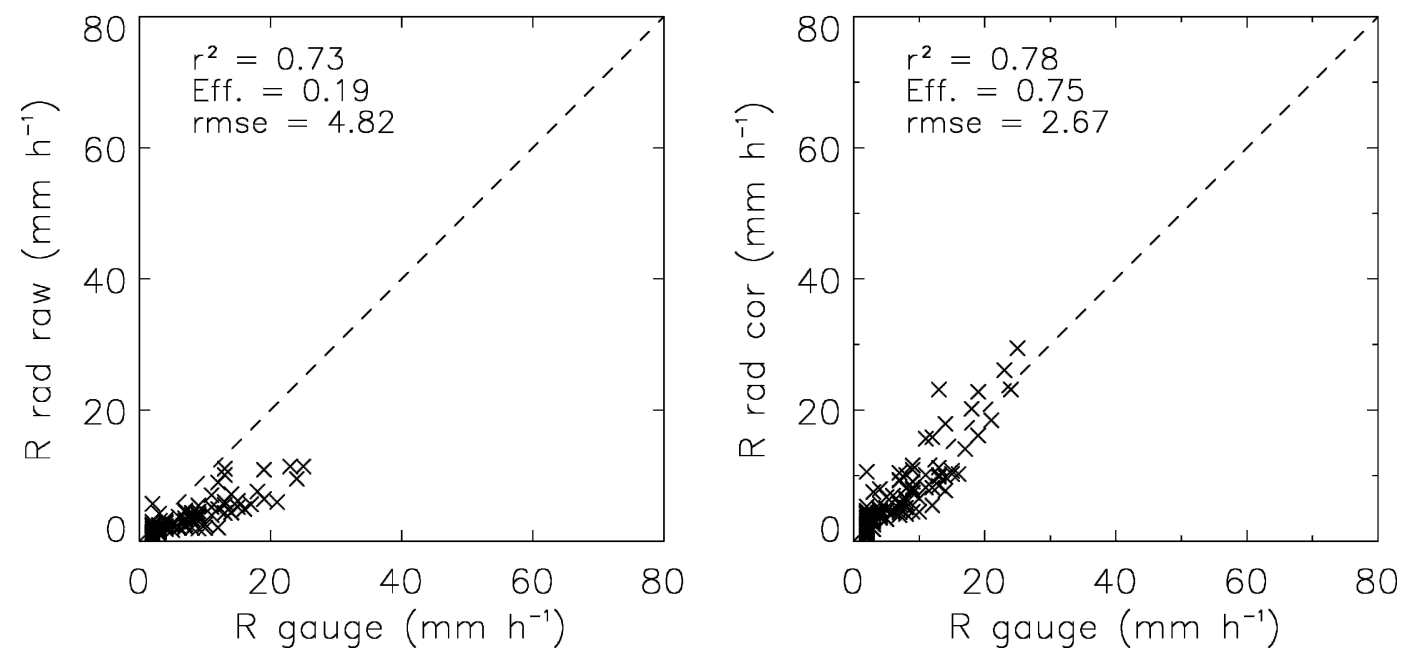

FIG. 7. Comparison of rain gauge rain rates with rain rates derived (left) from raw low-profile X-RHI measurements and (right) from corrected low-profile X-RHI measurements using the hybrid algorithm, for the three rain events. 

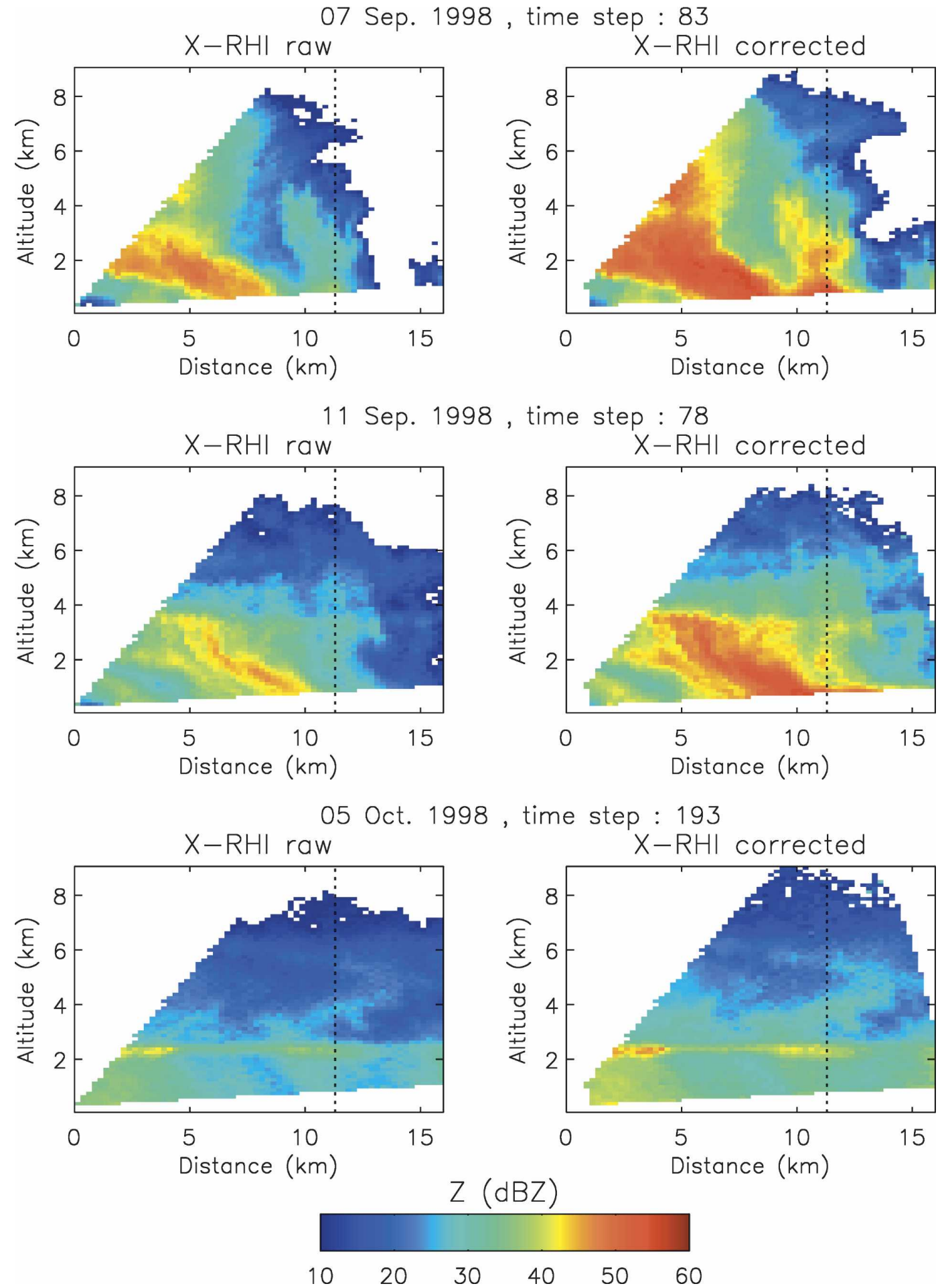

FIG. 8. Comparison of (left) raw and (right) corrected X-RHI images for the three rain events. The PIA is about $22 \mathrm{~dB}$ for the example taken during the $09 / 07$ rain event, about $21 \mathrm{~dB}$ for the $09 / 11$ rain event, and about $15 \mathrm{~dB}$ for the 10/05 rain event. The vertical dotted line figures the beam axis of the X-Pointer radar. 
TABLE 4. X-Pointer intercalibration relations and corresponding efficiency for the three rain events.

\begin{tabular}{ccc}
\hline \hline Date & Relation & Efficiency \\
\hline 07 Sep 1998 & $Z_{m}^{c}=0.81 Z_{m}+2.1$ & 0.52 \\
11 Sep 1998 & $Z_{m}^{c}=0.80 Z_{m}+5.5$ & 0.66 \\
05 Oct 1998 & $Z_{m}^{c}=0.89 Z_{m}+1.3$ & 0.62 \\
\hline
\end{tabular}

\section{b. X-pointer radar system}

Certainly, a necessary condition for multiradar compositing is to ensure accurate intercalibration of the radar systems. In the following we shall rely on the calibration of the X-RHI radar (obtained with the MRT and assessed in comparison with the rain gauge network) to calibrate the X-Pointer data. Following this, the attenuation affecting the X-Pointer measurements will be corrected.

\section{1) InTERCALIBRATION WITH THE X-RHI RADAR}

Following Cluckie et al. (2000), the possible calibration error of the X-Pointer radar may be compensated for using a linear correction,

$$
Z_{m}^{c}=A Z_{m}+B,
$$

where $(A, B)$ are two constants. Respectively, $Z_{m}$ and $Z_{m}^{c}$ are the measured and calibrated measured radar reflectivity factor, expressed in $\mathrm{dB} Z$. This formulation takes into account a possible error resulting from the incorrect application of the radar receiver slope. The $\mathrm{X}$-RHI radar has been calibrated using the MRT on the low profile. To intercalibrate the two radar systems, we use the intersection of the low profile of the X-RHI radar with the X-Pointer beam axis, at an altitude of about $800 \mathrm{~m}$. The X-Pointer reflectivity factors were then calibrated with a given set $(A, B)$ and the $\mathrm{X}$-Pointer attenuation is corrected using the HB algorithm. The stability of the HB algorithm should be certainly ensured, at least over the 800 first meters above ground level. Because the X-Pointer had no radome, the preliminary attenuation was assumed to be negligible. Next, the intercalibrated and attenuation-corrected measurements from both radars may be compared. The X-Pointer radar system is calibrated with the $(A, B)$ set, which induces the greatest proximity between the first principal component and the first bisector. Table 4 presents the optimal $(A, B)$ set obtained for the three rain events. One may notice that the intercalibration error of the X-Pointer radar is significant. According to the values of the slope coefficient of about 0.85 , a receiver calibration defect is most likely. Moreover, there is a systematic offset between 2 and
$5 \mathrm{~dB}$. This analysis must take into account the relative confidence in the X-RHI radar calibration, which may explain part of the difference in the offsets obtained for the three rain events.

\section{2) Attenuation correction using the HB ALGORITHM}

Because the X-Pointer is a vertically pointing radar, no PIA measurement is available, and so the MA or HY algorithms cannot be used. Because of the decrease of rain rate with altitude, we assumed that the PIA associated with the VPR is low enough to apply the $\mathrm{HB}$ algorithm for the attenuation correction of the X-Pointer measurements. As for the X-Pointer calibration, we assume the preliminary attenuation to be negligible. Figure 9 presents the PIA values deduced from the corrected X-Pointer measurements with time at the altitude of $4 \mathrm{~km}$. One may notice that the maximum PIA value is about $3 \mathrm{~dB}$ for the $09 / 07$ rain event, about $4 \mathrm{~dB}$ for the $09 / 11$ rain event, and about $7 \mathrm{~dB}$ for the 10/05 rain event. For the latter rain event, the high PIA is a result of two very brief but very intense cells just before time step 500. Nevertheless, the stability of the HB algorithm is thought to be ensured for such PIAs. These graphs also show that the X-Pointer measurements may be affected by nonnegligible attenuation effects during intense rain events. It must be also stressed that the choice of a unique DSD parameterization leads to erroneous attenuation correction in and above the bright band.

\section{Performance assessment}

We can now compare the raw, intercalibrated, and corrected HTIs in order to assess the relevance of the corrections performed. Practically, the HTIs derived from the X-RHI measurements begin at an altitude of about $800 \mathrm{~m}$, which is the altitude of the radar beam for the low profile above the Vernet site. Therefore, the HTIs derived from the X-Pointer measurements were truncated at $800 \mathrm{~m}$ as well for the calculations of the criteria and, therefore, the low-altitude region is not considered, despite the variability of the VPR measured by the X-Pointer radar in this region. As explained before, the criteria calculations are also truncated at an altitude of $4 \mathrm{~km}$ to remain below or at the melting layer altitude.

First, to analyze the improvement resulting from the intercalibration of the two radar systems, the quantitative comparison criteria calculated from the scatter diagrams are presented in Fig. 10. The bias is reduced as shown by the increase of the efficiency (from -0.11 , 

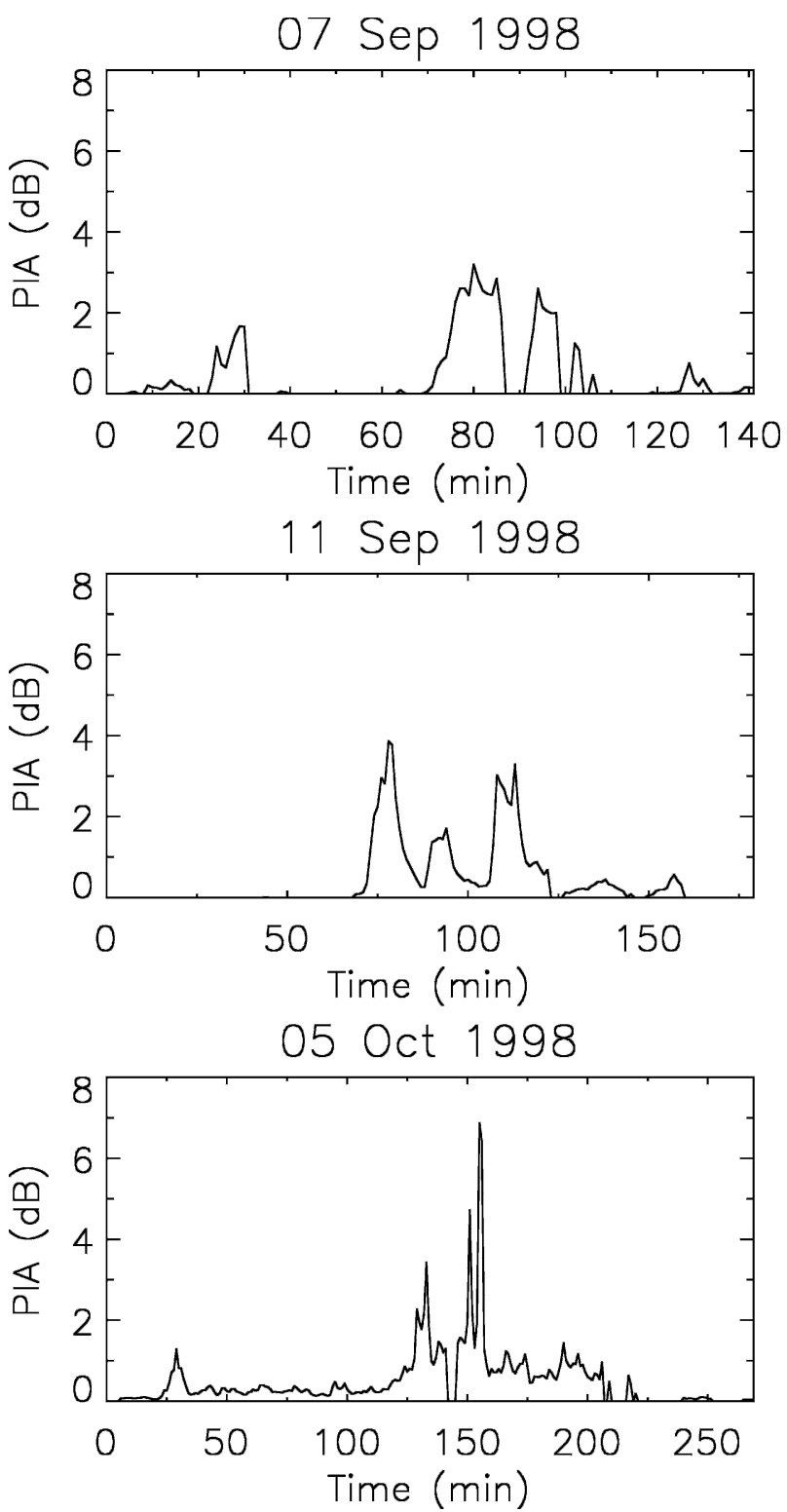

FIG. 9. PIAs (dB) derived from corrected X-Pointer measurement at the altitude of $4 \mathrm{~km}$, for the three rain events.

0.25 , and 0.45 to $-0.05,0.46$, and 0.73 for the three events, respectively) and by the decrease of the rmse (from 13.6, 8.98, and 6.53 to 10.75, 6.60, and 4.15). Nevertheless, the cofluctuation is not improved, as shown by the stability of the determination coefficient. It indicates that a bias still remains (the scatters are not aligned on the first bisector). The intercalibration is an important step, but the correction for the attenuation of the radar measurement is necessary.

Figure 11 presents the HTIs derived from the attenuation-corrected radar measurements for the three rain events. The X-RHI HTIs are the most influenced by the attenuation correction, which is consistent with the fact that the PIA was larger for the X-RHI measurements. In fact, the bright band is more contrasted for the 09/11 and 10/05 rain events. For the 09/11 event, the cell around time step 180 becomes quite comparable between the two radar systems. For the $10 / 05$ event, it is similar for the cell around time step 375 . The attenuation affecting the $\mathrm{X}$-Pointer measurements is also significant, as illustrated by the two very small and intense cells around time step 500, which becomes similar on the two HTIs after the attenuation correction. However, significant differences still remain. In particular, for the $09 / 07$ rain event, the correction applied to the X-RHI measurements around time step 100 is considerable, but still insufficient to be close to the corrected X-Pointer measurements. Similarly, considering the period around time step 75, a relatively intense cell between 5.5 and $6.5 \mathrm{~km}$ of altitude is seen by the X-RHI radar and not by the X-Pointer radar, despite the correction.

This qualitative analysis is confirmed by the quantitative comparison criteria that are calculated. The scatter diagrams of the corrected HTIs are shown in Fig. 12. One may observe an improvement for the $09 / 07$ and 09/11 rain events, because the points are globally closer to the first bisector and the dispersion decreases in comparison with the intercalibrated scatter diagrams. Quantitatively, it is shown by the increase of the determination coefficient (of about 0.2 ), the increase of the efficiency (of about 0.1), and the decrease of rmse (of about $1 \mathrm{dBZ}$ ). The comparison criteria remain almost unchanged for the 10/05 rain event. The determination coefficient slightly increases $(+0.02)$, which indicates a scatter shape that is closer to a straight line. However, the efficiency slightly decreases $(-0.04)$ and the rmse slightly increases $(+0.26 \mathrm{dBZ})$, which indicates that the dispersion increases. The attenuation correction does not significantly improve the consistency between the HTIs for the 10/05 rain event. It must be noted that the attenuation affecting the X-RHI measurements is less important for this rain event. The temporal integration to a 5-min time step improves again the consistency between the two radar datasets, which become very close for the 09/11 and 10/05 rain events $\left(r^{2}>0.8\right.$, Eff $\geq 0.8$, and rmse $<4.4$ ). The similarity between the two radar datasets is less clear for the 09/07 rain event, which is the most convective and intense rain event, and, thus, is the most affected by attenuation.

However, it must be noted that the comparison criteria we applied are strict because they are defined for 1D data series. Berne et al. (2004) used the obtained X-Pointer VPR to correct the measurements for the 

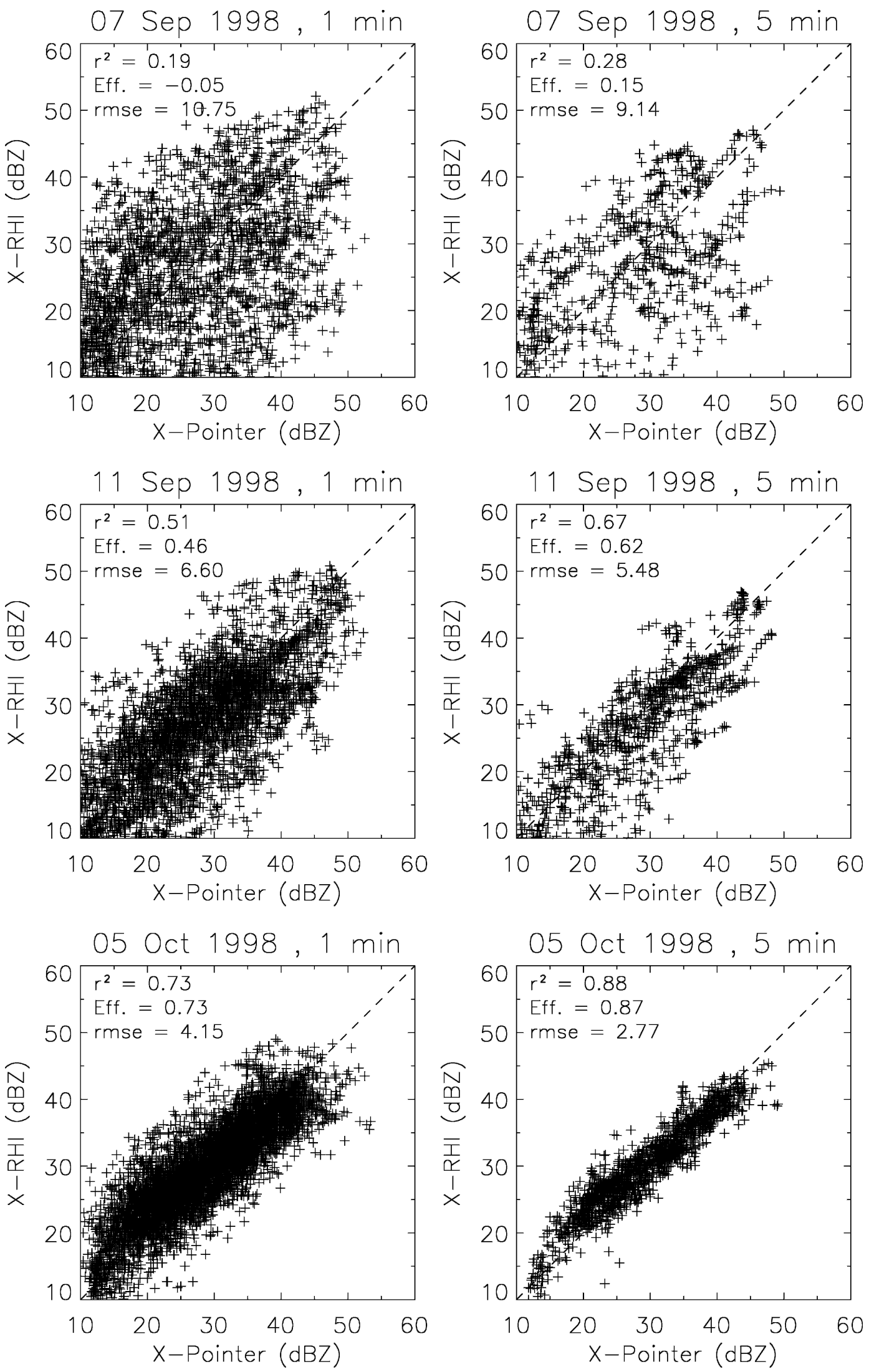

FIG. 10. Scatter diagrams for HTIs derived from intercalibrated X-RHI and X-Pointer measurements for the three rain events, at a time step of (left) 1 and (right) $5 \mathrm{~min}$. Only the points above $0.8 \mathrm{~km}$ and below $4 \mathrm{~km}$ of altitude are considered. 

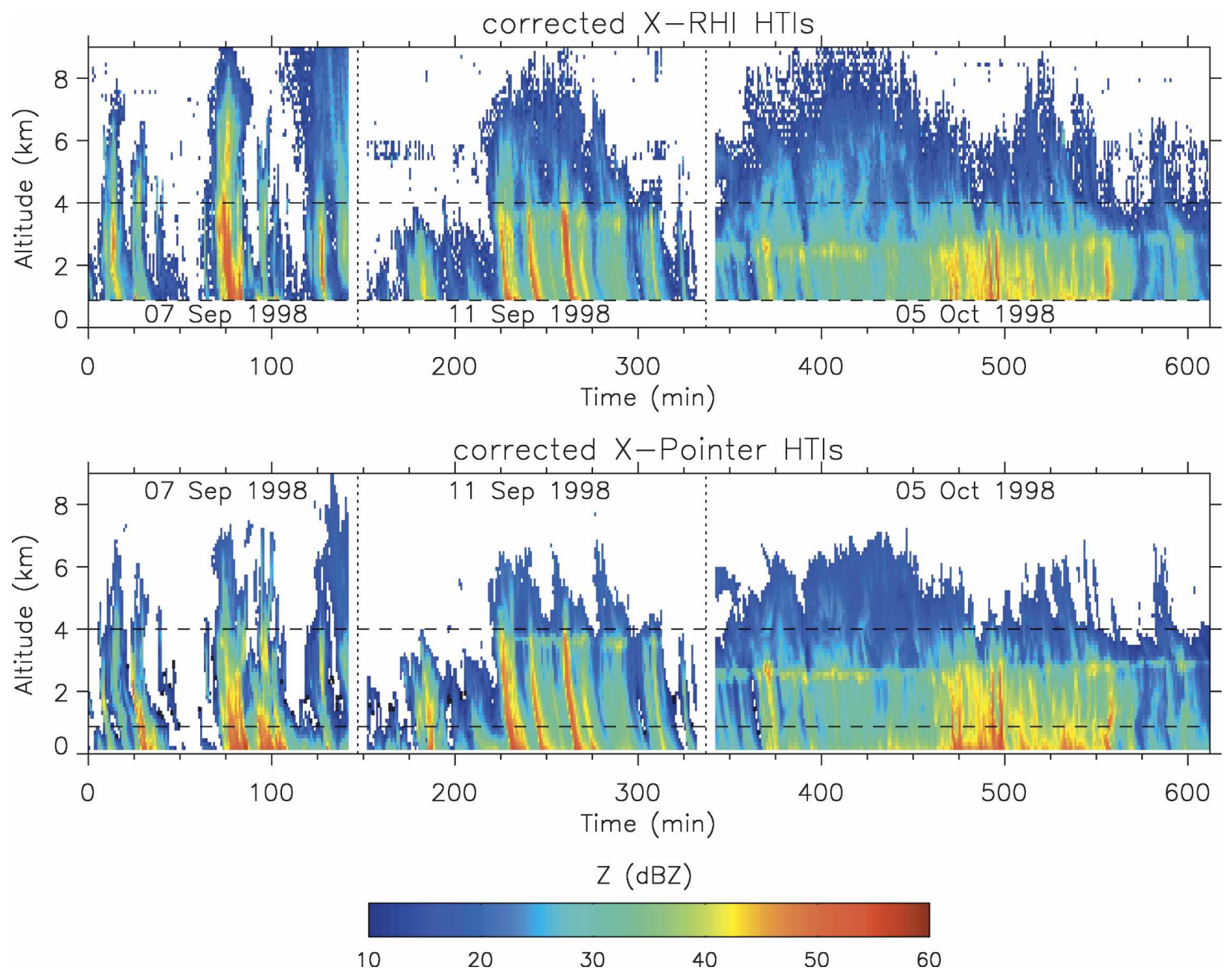

FIG. 11. HTIs derived from corrected (top) X-RHI and (bottom) X-Pointer measurements for the three rain events. The dashed lines indicate the range of altitude $(0.8 \leq h \leq 4 \mathrm{~km})$ on which the comparison criteria are calculated.

vertical heterogenity of rainfall from an S-band radar located at about $100 \mathrm{~km}$ of the studied area. The significant improvement of the cofluctuation of the rain gauge and S-band radar measurements (at a 6-min time step) shows that the performed calibration error and attenuation corrections are relevant, despite the remaining uncertainties. It also shows the likelihood of the strong reflectivity enhancements that are measured by the X-Pointer radar (see Fig. 11) in the first kilometer of altitude, and that cannot be confirmed by the $\mathrm{X}$-RHI measurements because they are mainly below the altitude of $800 \mathrm{~m}$ (figured by the dashed line in Fig. 11).

\section{Conclusions}

This article is focused on the assessment of the VPR for intense Mediterranean precipitation observed dur- ing HIRE'98. The work is based on the measurements of (i) an X-band vertically pointing radar (named $\mathrm{X}$-Pointer radar) and (ii) an X-band RHI scanning protocol radar (named X-RHI radar). For three intense rainfall events, the VPR was studied through the HTI. The HTIs derived from the two radar systems provide the opportunity to compare the radar measurements and to improve their consistency. An initial comparison was performed between the raw data and emphasized the general similarities, but also showed evidence of calibration and attenuation problems. The model used to parameterize the DSD and to provide consistent $(Z$, $k, R$ ) relations, based on Mie theory and rain-rate normalization, was detailed. The different attenuation correction algorithms have been described, and their limitations clearly defined. The calibration of each radar system has been adjusted before correcting for attenuation. The X-RHI radar was calibrated using the 

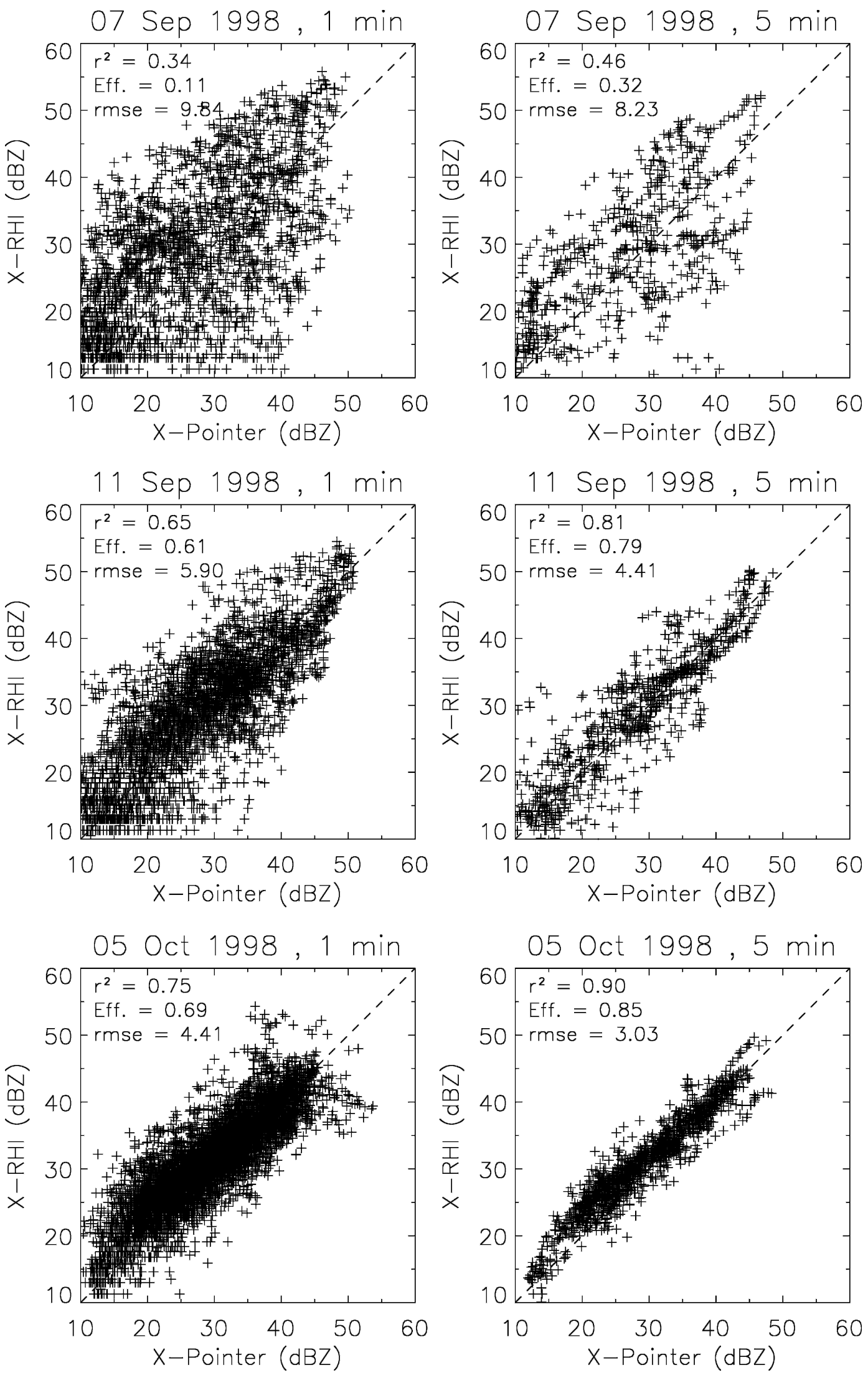

FIG. 12. Scatter diagrams for HTIs derived from corrected X-RHI and X-Pointer measurements for the three rain events, at a time step of (left) 1 and (right) $5 \mathrm{~min}$. Only the points above $0.8 \mathrm{~km}$ and below $4 \mathrm{~km}$ of altitude are considered. 
mountain reference technique. Attenuation was corrected for by the first low-elevation-angle X-RHI profile not affected by ground echo (designated as the low profile), using the PIA measurements derived from a mountain echo. To correct the entire RHI image, an algorithm based on inverse theory was implemented. The calibration of the X-Pointer is based on the corrected X-RHI low profile, in order to intercalibrate the two radar systems. The X-Pointer measurements have been corrected for attenuation using the HitschfeldBordan algorithm. Because of the limited PIA values encountered $(<7 \mathrm{~dB})$, the stability of this algorithm is ensured. Finally, a comparison between first the intercalibrated and then attenuation-corrected HTIs has quantitatively shown the improvement to the coherence of the two radar measurements. The importance of the calibration and attenuation corrections performed is, thus, confirmed. However, it also emphasized the limitations of these corrections as a result of the assumptions being made (e.g., the space-time uniformity of the DSD). The analysis of X-band radar measurements must be performed carefully because attenuation can generate considerable errors, even for vertical reflectivity profiles of just a few kilometers in range. Moreover, the correction techniques for X-band radar cannot totally reduce uncertainty resulting from attenuation.

The VPR estimation obtained is robust and consistent enough to be used for statistical analysis of the vertical structure of intense Mediterranean rainfall. Such an analysis is relevant to improve our understanding of the physical processes involved in the intense precipitations, as well as to investigate the influence of the vertical heterogeneity of rainfall on radar measurement (e.g., Berne et al. 2004).

This work is a preliminary step toward the combination of measurements from different radar systems dedicated to rain measurement. It shows the potential but also the difficulties that the multiradar rainfall estimation implies.

Acknowledgments. The authors thank the two anonymous reviewers for their helpful comments. The first author acknowledges financial support from the European Commission through a Marie Curie Postdoctoral Fellowship (Contract EVK1-CT-2002-50016). The authors would also like to express their thanks to Prof. I. Cluckie and to Dr. R. Griffith from WERMC for providing the X-Pointer radar data, and to Mr. P. Deshons for providing the City of Marseille rain gauge network data. HIRE'98 was supported by the European Commission (HYDROMET Project ENV4-CT96-0290 and ENV4-CT96-5030).

\section{REFERENCES}

Beard, K., 1976: Terminal velocity of cloud and precipitation drops aloft. J. Atmos. Sci., 33, 851-864.

Berne, A., G. Delrieu, A. Andrieu, and J.-D. Creutin, 2004: Influence of the vertical profile of reflectivity on radarestimated rain rates at short time steps. J. Hydrometeor., 5, 296-310.

Cluckie, I., R. Griffith, H. Lane, and K. Tilford, 2000: Radar hydrometeorology using a vertically pointing radar. Hydrol. Earth Syst. Sci., 4, 565-580.

Creutin, J.-D., and C. Obled, 1982: Objective analyses and mapping techniques for rainfall fields: An objective comparison. Water Resour. Res., 18, 413-431.

Delrieu, G., J.-D. Creutin, and I. Saint-Andre, 1991: Mean $K-R$ relationships: Practical results for typical weather radar wavelengths. J. Atmos. Oceanic Technol., 8, 467-476.

— - S. Caoudal, and J.-D. Creutin, 1997: Feasibility of using mountain return for the correction for ground-based X-band weather radar data. J. Atmos. Oceanic Technol., 14, 368-385.

_ L. Lucke, and J.-D. Creutin, 1999a: Attenuation in rain for $\mathrm{X}$-band and C-band weather radar systems: Sensitivity with respect to the drop size distribution. J. Appl. Meteor., 38, $57-68$.

— S. Serrar, E. Guardo, and J.-D. Creutin, 1999b: Rain measurement in hilly terrain with X-band weather radar systems: Accuracy of path-integrated attenuation estimates derived from mountain returns. J. Atmos. Oceanic Technol., 16, 405415.

Doviak, R., and D. Zrnic, 1993: Doppler Radar and Weather Observations. $2 \mathrm{~d}$ ed. Academic Press, $562 \mathrm{pp}$.

Fabry, F., and I. Zawadzki, 1995: Long-term observations of the melting layer of precipitation and their interpretation. $J$. Atmos. Sci., 52, 838-851.

Haddad, Z., E. Im, and S. Durden, 1995: Intrinsic ambiguities in the retrieval of rain rates from radar returns at attenuating wavelengths. J. Appl. Meteor., 34, 2667-2679.

Hitschfeld, W., and J. Bordan, 1954: Errors inherent in the radar measurements of rainfall at attenuating wavelengths. $J$. Meteor., 11, 58-67.

Joss, J., and A. Waldvogel, 1990: Precipitation measurement and hydrology. Radar in Meteorology: Battan Memorial and 40th Anniversary Radar Meteorology Conference, D. Atlas, Ed., Amer. Meteor. Soc., 577-606.

Marshall, J., W. Hitschfeld, and K. Gunn, 1955: Advances in radar weather. Advances in Geophysics, Vol. 2, Academic Press, $1-56$.

Marzoug, M., and P. Amayenc, 1994: A class of single- and dualfrequency algorithms for rain-rate profiling from a space born radar. Part I: Principle and tests from numerical simulations. J. Atmos. Oceanic Technol., 11, 1480-1506.

Menke, W., 1989: Geophysical Data Analysis: Discrete Inverse Theory. International Geophysics Series, Vol. 45, Academic Press, $289 \mathrm{pp}$.

Nash, J., and J. Sutcliffe, 1970: River flow forecasting though conceptual models. I. A discussion of principles. J. Hydrol., 10, 282-290.

Pellarin, T., G. Delrieu, G. Saulnier, H. Andrieu, B. Vignal, and J.-D. Creutin, 2002: Hydrological visibility of weather radar systems operating in mountainous region: Case study for the Ardche catchment (France). J. Hydrometeor., 3, 539-555. 
Salles, C., D. Sempere-Torres, and J.-D. Creutin, 1999: Characterisation of raindrop size distribution in mediterranean climate: Analysis of the variations on the Z-R relationship. Preprints, 29th Int. Conf. on Radar Meteorology, Montreal, QC, Canada, Amer. Meteor. Soc., 670-673.

Sempere-Torres, D., J. Porrà, and J.-D. Creutin, 1994: A general formulation for raindrop size distribution. J. Appl. Meteor., 33, 1494-1502.

Serrar, S., G. Delrieu, J.-D. Creutin, and R. Uijlenhoet, 2000: Mountain reference technique: Use of mountain returns to calibrate weather radars operating at attenuating wavelengths. J. Geophys. Res., 105, 2281-2290.

Uijlenhoet, R., and Coauthors, 1999: HYDROMET Integrated Radar Experiment (HIRE): Experimental setup and first results. Preprints, 29th Int. Conf. on Radar Meteorology, Montral, QC, Canada, Amer. Meteor. Soc., 926-930.

Vignal, B., H. Andrieu, G. Delrieu, and J.-D. Creutin, 2003: Identification of rain-rate profiles from radar returns at attenuating wavelengths using an inverse method: A feasibility study. J. Appl. Meteor., 42, 1014-1030. 